\title{
Activation of pelvic floor, lumbar and abdominal musculature during a simulated manual material handling task: a cross-sectional study
}

Ativação do assoalho pélvico, musculatura lombar e abdominal durante uma tarefa simulada de manuseio de material: um estudo transversal

Activación del diafragma pélvico, de la musculatura lumbar y abdominal durante una actividad simulada de manejo de material: un estudio transversal

Fernanda Cabegi de Barros', Patricia Driusso², Fernanda Roberto ${ }^{3}$, Mariana Vieira Batistão ${ }^{4}$, Mikaela Corrêa ${ }^{5}$, Tatiana de Oliveira Sato ${ }^{6}$

\begin{abstract}
I Pelvic floor muscles act synergistically with the abdominal and lumbar muscles contributing to spine and pelvic control. These muscles are activated during activities that increase intra-abdominal pressure, such as manual material handling. The aim of our study was to assess the electrical activity of the lumbar, abdominal and pelvic floor muscles during manual material handling with different loads. This is a cross-sectional study with sixteen nulliparous continent women aged between 18 and 35 years. An electromyographic system was used to evaluate the activation of the multifidus, erector spinal (iliocostal) and abdominal rectus muscles bilaterally (Trigno Wireless $^{\oplus}$, DelSys ${ }^{\circledR}$, Boston, USA) and another for the pelvic floor muscles (Thought Technology Ltd, Canadá). Electromyographic data were collected during manual handling of three loads: light ( $1.5 \mathrm{~kg}$ ), medium (4.5 kg) and heavy $(11.3 \mathrm{~kg})$. Repeated measures ANOVA was applied to compare the activation among loads at a $5 \%$ level of significance ( $\alpha=0.05$ ). There was a significant increase in the activation of the lumbar and abdominal musculature as the load increases. No difference among loads was found for the pelvic floor muscle activation. Pelvic floor muscles did not increase their activation in function of the load, as occur for the lumbar and abdominal muscles
\end{abstract}

in nulliparous continent women. These findings need to be confirmed for incontinent woman, since it could have clinical implications for designing both occupational tasks and pelvic floor rehabilitation.

Keywords I Pelvic Floor Muscle; Electromyography; Women's Health; Ergonomics.

RESUMO I Os músculos do assoalho pélvico agem sinergicamente com os músculos abdominais e lombares, contribuindo para o controle da coluna e da pelve. Esses músculos são ativados durante atividades que aumentam a pressão intra-abdominal, como o manuseio manual do material. O objetivo deste estudo foi avaliar a atividade elétrica dos músculos do assoalho pélvico, coluna lombar e abdominais durante o manuseio manual do material com diferentes cargas. Trata-se de um estudo transversal com 16 mulheres nulíparas do continente com idade entre 18 e 35 anos. Utilizou-se um sistema eletromiográfico para avaliar a ativação dos músculos multífidos, eretor da coluna (iliocostal) e reto abdominal, bilateralmente (Trigno Wireless ${ }^{\circledast}$, DelSys $^{\circledast}$, Boston, EUA) e outro sistema para os músculos do assoalho pélvico (Thought Technology Ltd, Canadá). Os dados eletromiográficos foram coletados durante o

This study was developed at the Physical Therapy Department of the Universidade Federal de São Carlos.

Universidade Federal de São Carlos (UFSCar) - São Carlos (SP), Brazil. E-mail:barros.fernandac@gmail.com. Orcid: 0000-0003-1541-9907 2Universidade Federal de São Carlos (UFSCar) - São Carlos (SP), Brazil. E-mail: pdriusso@ufscar.br. Orcid: 0000-0001-8067-9786 3Universidade Federal de São Carlos (UFSCar) - São Carlos (SP), Brazil. E-mail: fernanda.roberto5@gmail.com. Orcid: 0000-0002-3195-4865 ${ }^{4}$ Universidade Federal de São Carlos (UFSCar) - São Carlos (SP), Brazil. E-mail: marivbatistao@gmail.com. Orcid: 0000-0003-1397-881X 5 Universidade Federal de São Carlos (UFSCar) - São Carlos (SP), Brazil. E-mail: mikaela.sicorrea@gmail.com. Orcid: 0000-0002-1567-2542 6Universidade Federal de São Carlos (UFSCar) - São Carlos (SP), Brazil. E-mail: tatisato@gmail.com. Orcid: 0000-0001-8797-8981 
manuseio manual de três cargas: leve (1,5kg), média $(4,5 \mathrm{~kg})$ e pesada (11,3kg). Medidas repetidas Anova foram aplicadas para comparar a ativação entre cargas e o nível de significância foi estabelecido em 5\% ( $\alpha=0,05)$. Houve um aumento significativo na ativação da musculatura lombar e abdominal à medida que a carga aumentou. Não foi encontrada diferença entre as cargas para a ativação dos músculos do assoalho pélvico. Os músculos do assoalho pélvico não aumentaram sua ativação de acordo com a carga manuseada, como ocorre nos músculos lombar e abdominal em mulheres continentes e nulíparas. Esses achados precisam ser confirmados para mulheres incontinentes, pois podem ter implicações clínicas para o planejamento de tarefas ocupacionais e para a reabilitação do assoalho pélvico.

Descritores | Diafragma da Pelve; Eletromiografia; Saúde da Mulher; Ergonomia.

RESUMEN | Los músculos del piso pélvico actúan sinérgicamente con los músculos abdominales y lumbares contribuyendo al control de la columna y la pelvis. Estos músculos se activan durante actividades que aumentan la presión intraabdominal, como el manejo manual de material. El objetivo de este estudio fue evaluar la actividad eléctrica de los músculos del piso lumbar, abdominal y pélvico durante el manejo manual del material con diferentes cargas. Este es un estudio transversal con dieciséis mujeres continentes nulíparas de edades comprendidas entre 18 y 35 años. Se usó un sistema electromiográfico para evaluar la activación de los músculos multifido, erector espinal (iliocostal) y recto abdominal bilateralmente (Trigno Wireless ${ }^{\circledR}$, DelSys ${ }^{\circledast}$, Boston, EE. UU.) y otro para los músculos del piso pélvico (Thought Technology Ltd, Canadá). Los datos electromiográficos fueron recolectados durante el manejo manual de tres cargas: ligera $(1.5 \mathrm{~kg})$, mediana $(4.5 \mathrm{~kg})$ y pesada $(11.3 \mathrm{~kg})$. Se aplicaron medidas repetidas ANOVA para comparar la activación entre cargas y el nivel de significancia se estableció en $5 \%(\alpha=0.05)$. Hubo un aumento significativo en la activación de la musculatura lumbar y abdominal a medida que aumenta la carga. No se encontraron diferencias entre las cargas para la activación de los músculos del piso pélvico. Los músculos del piso pélvico no aumentaron su activación de acuerdo con la carga manejada, como ocurre con los músculos lumbares y abdominales en las mujeres continentes nulíparas. Estos hallazgos deben confirmarse para la mujer incontinente, ya que podría tener implicaciones clínicas para el diseño de tareas ocupacionales y la rehabilitación del piso pélvico.

Palabras clave | Diafragma Pélvico; Electromiografía; Salud de la Mujer; Ergonomía.

\section{INTRODUCTION}

Pelvic floor muscles (PFMs) are responsible for several functions, namely: maintenance of urinary and fecal continence, support of abdominal and pelvic organs, sexual functioning, support of the spine and pelvis, aid in increasing intra-abdominal pressure and respiration, spinal stability and postural control ${ }^{1,2}$. Some factors may compromise the functioning of this muscle group, such as weight gain, aging, gestation and childbirth ${ }^{2}$. These situations may predispose PFM dysfunctions, such as urinary and/or fecal incontinence, urogenital dystopia, and sexual dysfunction ${ }^{3}$.

Some studies have shown that PFMs act synergistically with the abdominal muscles when there is an increase in intra-abdominal pressure, e.g. cough, material handling, change of decubitus or during pregnancy, to minimize the inferior displacement of the PFMs, maintain the placement of the bladder neck, assist in the closure of the urethral and anal sphincter and contribute to the control of the spine and pelvis ${ }^{4}$.

The electromyographic activity of PFMs increases before the activity of upper and lower limbs, in a pre-programmed postural component ${ }^{1,5}$. However, only one study evaluating the electrical activity of PFMs during manual material handling task was found ${ }^{6}$. The authors found that the amplitude of PFM activation during manual handling is greater than in the supine position. This result is relevant due to the information on the trunk and PFM activation.

However, studies have focused on isolated maximal voluntary contractions to study the $\mathrm{PFMs}^{7}$. Thus, understanding the mechanisms of muscle activation of PFMs and abdominal and lumbar muscles during functional activities is important to develop effective physical therapy treatments for PFM dysfunctions and design occupational tasks. The evaluation of PFM activation during occupational activities still needs to be better explored, evaluating different loading conditions and the pattern of activation of trunk and pelvic floor muscles. These findings can bring new ideas for manual material handling training for continent and incontinent workers.

Thus, the aim of our study was to evaluate the electrical activity of the PFMs, lumbar and abdominal muscles during a simulated manual material handling task with 
different loads to verify how the handling and the loads interfere in the activation of these muscles in continent young women.

\section{METHODOLOGY}

\section{Study design and subjects}

This is a cross-sectional, laboratory-based study, with quantitative analysis and data collection performed between June 2014 and August 2015. This study was approved by the Comitê de Ética em Pesquisa em Seres Humanos da Universidade Federal de São Carlos (CAAE: 34211114.2.0000.5504, Opinion: 869223). All women who voluntarily agreed to participate in the study signed an informed consent form.

The sample was composed by sixteen women, aged between 18 and 35 years. This age range was chosen to include adult and young women, to avoid factors that could influence the PFM function, such as changes due to aging and climacteric. Participants were invited by the dissemination of the study on local radio and social media. The participants answered an anamnesis that, in addition to personal data, addressed questions about gynecological, obstetric and orthopedic injury history. The women selected were nulliparous, continent, eutrophic, who could voluntarily contract the PFMs and with active sexual life in the prior 6 months. The exclusion criteria were: self-reported low back pain in the prior 12 months, dysmenorrhea in the prior 3 months, knee pain, pelvic surgery, difference in leg length (apparent or real) greater than 3 centimeters, genital prolapse and urinary incontinence.

The sample was estimated using the $\mathrm{G}^{*}$ Power program (3.1.5, Germany). To estimate the sample size, we considered the application of the repeated measures ANOVA, with a large effect size $(\mathfrak{f} 2=0.35)$; an $80 \%$ power and a $5 \%$ significance level, which resulted in 15 subjects.

\section{Evaluations}

\section{Questionnaires}

The evaluation was performed on two different days. At the first day, the participants answered questionnaires and performed the pelvic floor functional evaluation. At the second day, the participants performed the manual material handling tasks. The questionnaires had questions on personal information, general health and disorders of the genitourinary system (King's Health Questionnaire) $)^{8}$.

The King's Health Questionnaire (KHQ) was used to assess the urinary incontinence (UI) symptoms and its influence on the quality of life. The KHQ is composed of 21 questions that correspond to eight domains: general health perception, impact of urinary incontinence, limitations of daily activities, physical limitations, social limitations, personal relationship, emotions, sleep/energy. It also has a scale for measuring UI severity and a scale that assesses presence and intensity of urinary symptoms. The KHG does not present a general score, but a score by domains. The score ranges from 0 to 100 , the higher the score, the worse the quality of life corresponding to the respective domain ${ }^{8}$.

The Nordic Musculoskeletal Questionnaire (NMQ) was also applied ${ }^{9}$. The NMQ consists of questions about the occurrence of symptoms at the neck, shoulders, upper back, elbows, lower back, wrist/hands, hips/thighs, knees, and ankle/feet. The respondent should report the occurrence of symptoms considering the 12 months and seven days preceding the interview, as well as report the occurrence of pain interference in daily activities in the last year and the search for a health professional. The results from the King's Health Questionnaire and the NMQ were used to apply the exclusion criteria.

The Baecke Habitual Physical Activity Questionnaire was applied to characterize the sample. The Baecke questionnaire is composed of 16 questions covering three habitual physical activity domains in the prior12 months: 1) occupational physical activity with eight questions, 2) physical exercise during sports with four questions, 3) physical activity during leisure and locomotion with four questions ${ }^{10}$.

\section{Pelvic Floor Mus cle Function}

The function of pelvic floor was assessed using the PERFECT system and the manometry. The participants were positioned in dorsal decubitus, with hip and knee flexion, according to the protocol proposed by Laycock and Jerwood ${ }^{11}$. The physical therapist introduced one finger into the vagina of the participant to perform the vaginal palpation, and the participant was instructed to contract the PFMs with the maximum strength (Power). The participants were instructed only by verbal command on how to contract the musculature, without the use of accessory musculature.

The classification of the degree of strength of the participants (Power) was obtained according to the 
Oxford Modified Scale and PERFECT Scheme ${ }^{11}$. The contraction pressure was graded as: 0 : Nil, 1 : Flicker, 2:Weak, 3: Moderate, 4: Good or 5: Strong ${ }^{11}$. Subsequently, the participants were instructed to contract with the greatest strength and for the longest time possible (Endurance), in which the contraction maintenance, in seconds, was recorded. The participant was then instructed to successively contract with the maximum strength and the maximum time reached in the previous stage, until muscle fatigue (Repeat), and ended with fast contractions of the PFMs with the maximum strength the greatest number of times (Fast), and the number of contractions were recorded. The participants had one minute of rest between each stage of PFM evaluation.

\section{Equipment}

\section{Manometry}

The maximum voluntary contraction was recorded using a manometer (Peritron Cardio Design Pty Ltd, Oakleigh, Victoria, Australia) five minutes after the end of digital palpation. This device has a graduation from 0 to $300 \mathrm{~cm} \mathrm{H}_{2} \mathrm{O}$ and is equipped with a vaginal probe $(28 \times 55$ $\mathrm{mm}$ ). The participants were in dorsal decubitus, with hip and knee flexion. The vaginal sensor was introduced about $3.5 \mathrm{~cm}$ into the vagina and the resting vaginal pressure (without voluntary contraction of PFMs) was collected. The apparatus was then calibrated, and the participant was instructed to perform three-second contractions of the PFMs as instructed by an "inward and upward" movement with the greatest strength possible and avoiding the use of abdominal, gluteal and hip muscles. Three contractions were performed with a one-minute interval between each contraction. The peak value of the three maximum voluntary contractions was used for data analysis.

\section{Surface electromyography}

The electromyographic signal of the erector muscles of the spine (iliocostal portion), the rectus abdominis muscle and the lumbar multifidus muscle were recorded bilaterally with a wireless system (Trigno Wireless ${ }^{\circledR}$, DelSys ${ }^{\circledR}$, Boston, USA) at a sampling frequency of $2000 \mathrm{~Hz}$. The sensors used have detection geometry in two parallel bars of silver (99.9\%) and simple differentiation. The characteristics of the active electrodes are: CMRR greater than $80 \mathrm{~dB} ; 10 \mathrm{~V} / \mathrm{V}$ voltage gain; $0.75 \mu \mathrm{V}$ noise ratio (RMS). The signals were conditioned by the main amplifier (Trigno Recharging Base Station, DelSys ${ }^{\circledR}$, Boston, USA), with a $1000 \mathrm{~V} / \mathrm{V}$ gain, a $20-450 \mathrm{~Hz}$ frequency band, a 16 -bit resolution and a $0.5 \mu \mathrm{V}$ noise (RMS).
The electrical activity of the PFMs was recorded using the Myotrac Infiniti system (Thought Technology Ltd, Canada), with an $1 \mathrm{KHz}$ acquisition frequency and a $0.5 \%$ gain accuracy. The electrical activity of the PFMs was acquired by a vaginal electrode (AS 9572, Thought Technology Ltd, Canada) with two stainless steel electrodes (length: $3.5 \mathrm{~cm}$; width: $1.0 \mathrm{~cm}$ ), a 10 $\mathrm{G} \Omega$ input impedance and $10^{-1} \mathrm{KHz}$ frequency band and common rejection mode (CMRR) rate $>130 \mathrm{~dB}$. A surface electrode (Medi-Trace) was used as reference.

\section{Inclinometry}

Lumbar movements were recorded by two inclinometer sensors based on triaxial accelerometers and one acquisition unit (Logger Teknologi HB, Akarp, Sweden). The acquisition frequency was $20 \mathrm{~Hz}$. Before data collection, the sensors were calibrated on a straight surface, parallel to the ground, for each of their faces for 5 seconds ${ }^{12}$. One transducer was placed in the right side of the $12^{\text {th }}$ thoracic vertebra level (T12) and another to the sacrum (S1) to evaluate the lumbar movement. The reference position was recorded with the participant in the upright posture, looking a mark at eye level 1 meter away from the subject. The 90th percentile, indicating lumbar flexion and lateral inclination, was estimated.

\section{Procedures}

\section{Surface electromyography of spinal muscles}

The sensors were attached parallel to the muscle fibers with detection bars perpendicular to the fibers. The sensor was coupled to the skin by a double-sided adhesive (DelSys $\left.{ }^{\circledR}\right)$. Before fixing the electrodes, the skin was trichotomized and cleaned with alcohol $70 \%$. In this equipment, the reference register ("ground electrode") is one of the four bars contained in the sensor.

With the participant positioned in ventral decubitus, for the erector of the spine in the iliocostal portion, the electrodes were positioned one finger medially to the line formed between the posterior superior iliac spine and the lowest point of the last rib (at the level of the L2 vertebra) $)^{13}$. For the multifidus muscle, the electrodes were positioned at the level of the spinous process of L5 and aligned with a line from the posterolateral iliac spine to the interspace between L1 and L2 (Figure 1A) ${ }^{13}$. For the rectus abdominis muscle, sensors were placed $1 \mathrm{~cm}$ above the umbilical scar and $2 \mathrm{~cm}$ lateral to the midline, with the subject lying in the dorsal decubitus position (Figure $1 \mathrm{~B})^{13}$. 

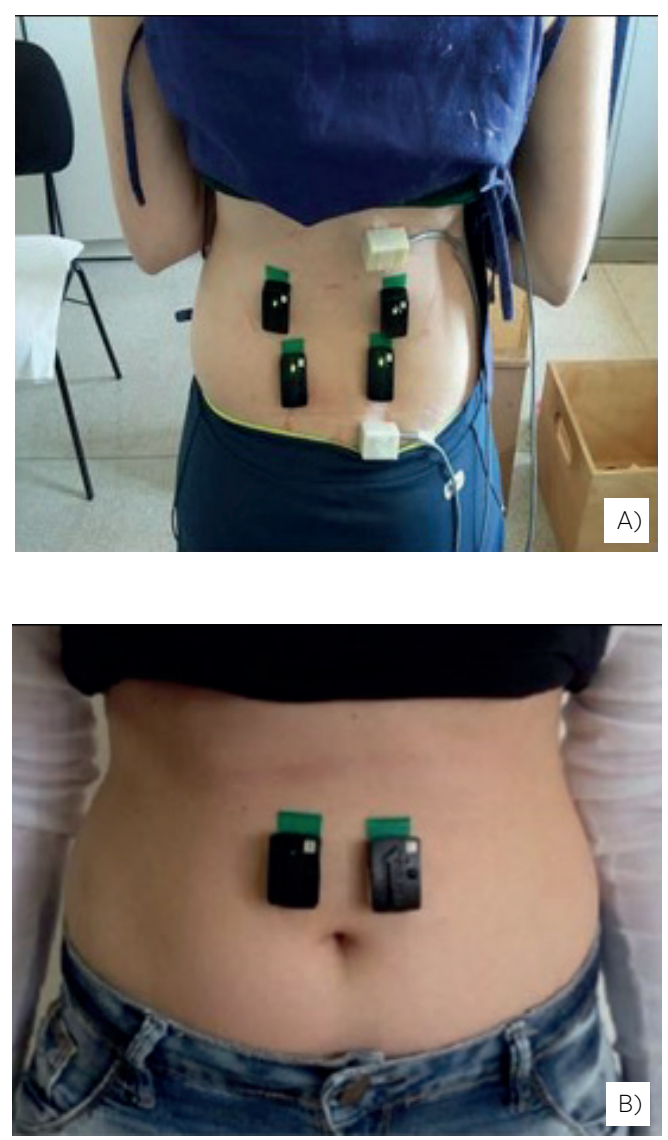

Figure 1. A) Electromyographic sensors (black, wireless) for lumbar muscles and inclinometer sensors (white). B) Electromyographic sensors for abdominal muscles

Three trials of maximal isometric voluntary contraction of each muscle were performed. For the erector spinae and multifidus muscles, trunk extension was performed from the prone position during 5 seconds $^{13}$. For the rectus abdominis muscle, an isometric abdominal contraction was performed with the subject in dorsal decubitus with hip and knee flexion and supported, trunk flexion was performed from the supine position during 5 seconds ${ }^{14}$. The contractions were repeated three times, with one minute of rest. The signals were packed by the main amplifier (Trigno Charging Base Station, DelSys ${ }^{\circledR}$, Boston, USA). The effective EMG signal gain was 909 $\mathrm{V} / \mathrm{V}$, with a 16-bit resolution and $0.5 \mathrm{mV}$ noise (RMS).

Data processing was performed from a routine programmed in MatLab ${ }^{\circledR}$ (version 7.0.1, MathWorks Inc., Natick, USA). After the recording, the signal was corrected for DC offset, then bandpass $(30-450 \mathrm{~Hz}-4$ th order Butterworth filter, phase delay zero) and notch $(60,120,180, \ldots \mathrm{Hz})$ filtered, thus virtually eliminating artifacts $^{15}$. The Root Mean Square (RMS) values were obtained in $200 \mathrm{~ms}$ windows without overlap. The signal was corrected for DC offset.

\section{Surface electromyography of pelvic floor muscles}

The vaginal electrode was inserted $3.5 \mathrm{~cm}$ into the vaginal introitus and the steel plates were positioned laterally in the vagina towards the ischial tuberosity. The reference electrode was positioned on the anterosuperior iliac crest.

The maximum voluntary contraction of the PFMs was performed with the volunteer in a supine position. The participant was instructed to perform the contraction of the PFMs with an "in and up" movement, for five seconds, with the greatest strength possible. A familiarization contraction and three contractions were performed, with orientation to avoid the use of the abdominal, gluteus and hip adductor muscles ${ }^{16}$.

The data from the electrical activity of the PFMs were filtered by an analog bandpass filter of 20 to 500 $\mathrm{Hz}$ and then analogically transformed into RMS values. The electromyographic data processing was performed using Matlab R2008a software. To determine peak and mean contraction of electromyographic data during maximal voluntary contraction, the data were rectified (full-wave rectification) and analyzed by estimating the RMS with a window of 40 ms and a $50 \%$ overlap.

\section{Tasks}

The participants performed an experimental protocol based on previous studies on manual material handling tasks performed by the female population ${ }^{17,18}$. One box was designed to allow a good handle without requiring abduction of the shoulder joint ${ }^{19}$. The participants were instructed to perform the following tasks:

I) Sustain the load: remain standing still for 15 seconds, holding the box close to the body, with $90^{\circ}$ elbow flexion and $0^{\circ}$ shoulder flexion;

II) Handling the load without trunk rotation: displacement of the box between floor and the greater trochanter height, in front of the body, simulating lifting and lowering the load. This task was performed 12 times during 1-minute;

III)Handling the load with trunk rotation: moving the box, starting at the front of the subject, at greater trochanter height and ending at the floor level, alternating right and left sides. This task was performed 12 times during 1-minute.

Each task was performed three times, with light $(1.5 \mathrm{~kg})$, medium $(4.5 \mathrm{~kg})$ and heavy $(11.3 \mathrm{~kg})$ loads. After each task, a 2-minute rest was allowed to avoid muscle fatigue. The order of the tasks was randomized. Figure 2 shows the data collection setup and Figure 3 shows raw data from one subject. 

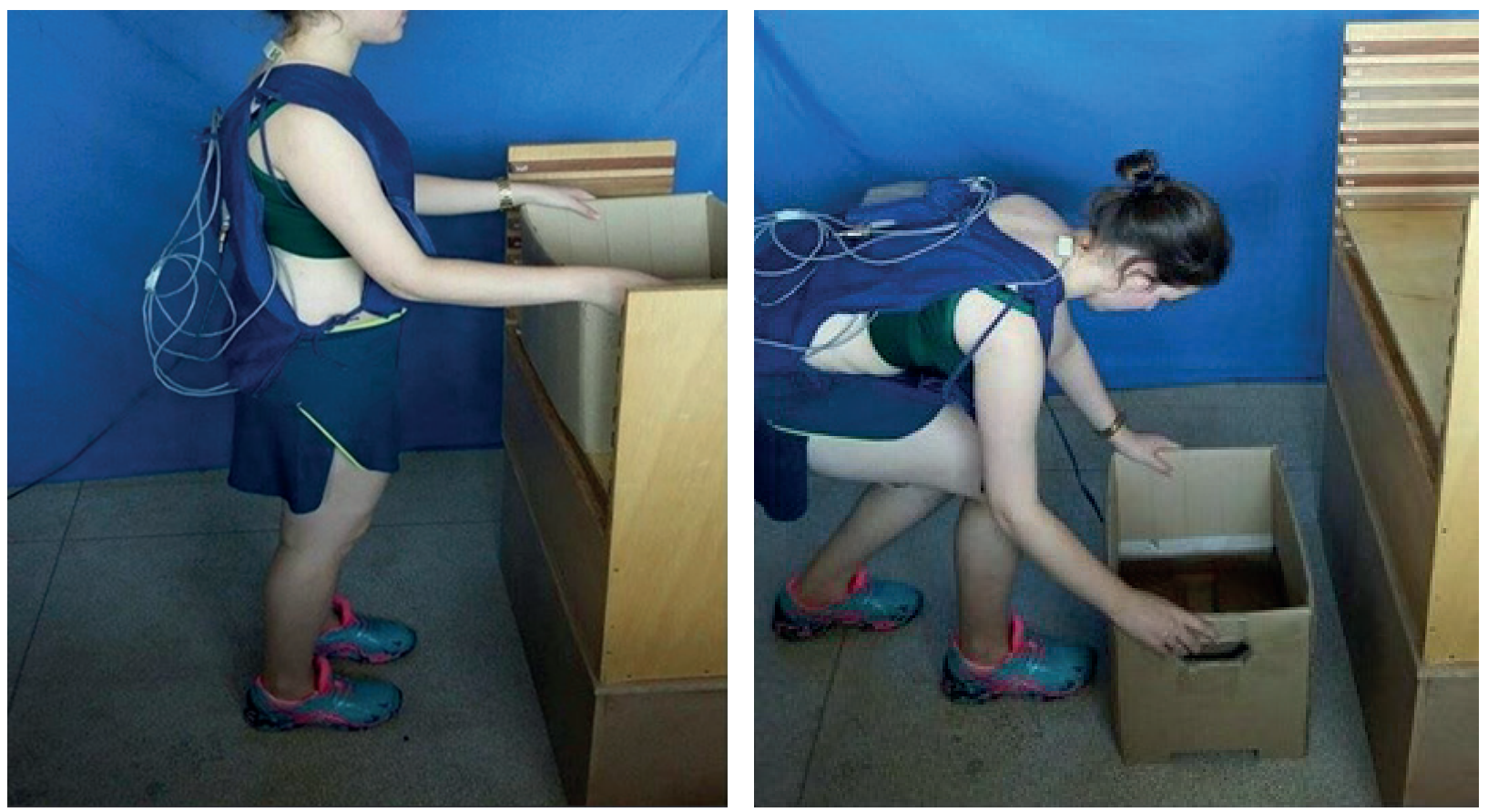

Figure 2. Data collection setup

A) $\mu \mathrm{V}$

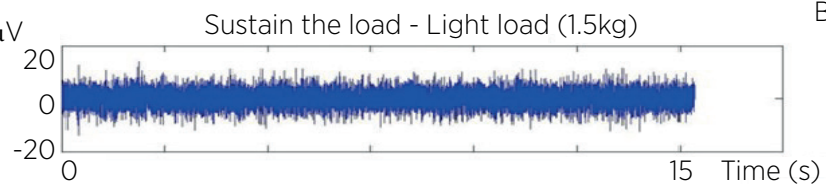

$\mu \mathrm{V}$
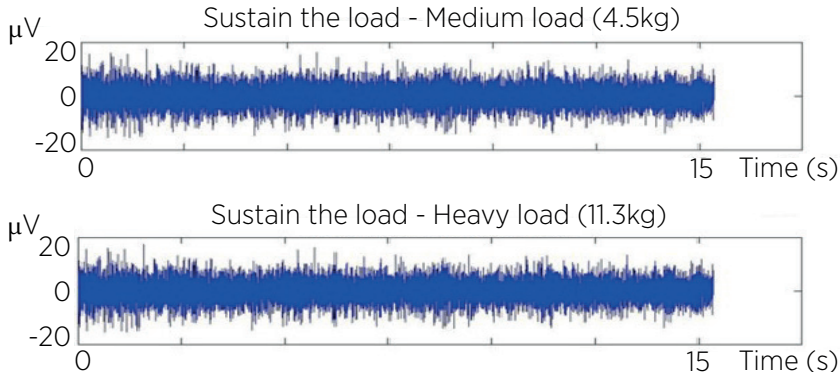

B)

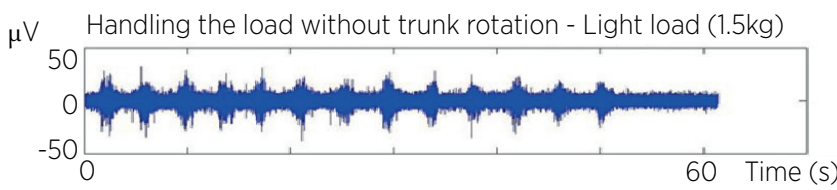

$\mu \mathrm{V} \quad$ Handling the load without trunk rotation - Medium load (4.5kg)

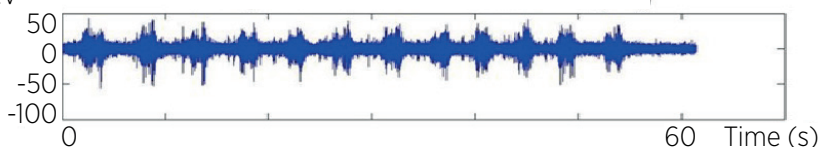

$\mu \mathrm{V} \quad$ Handling the load without trunk rotation - Heavy load (11.3kg)

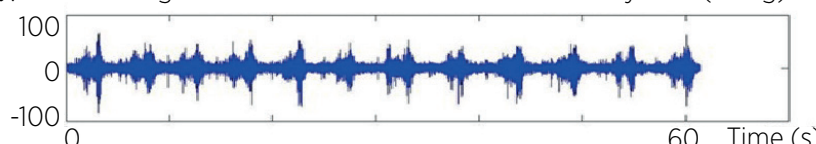

C) $\mu \mathrm{V}$
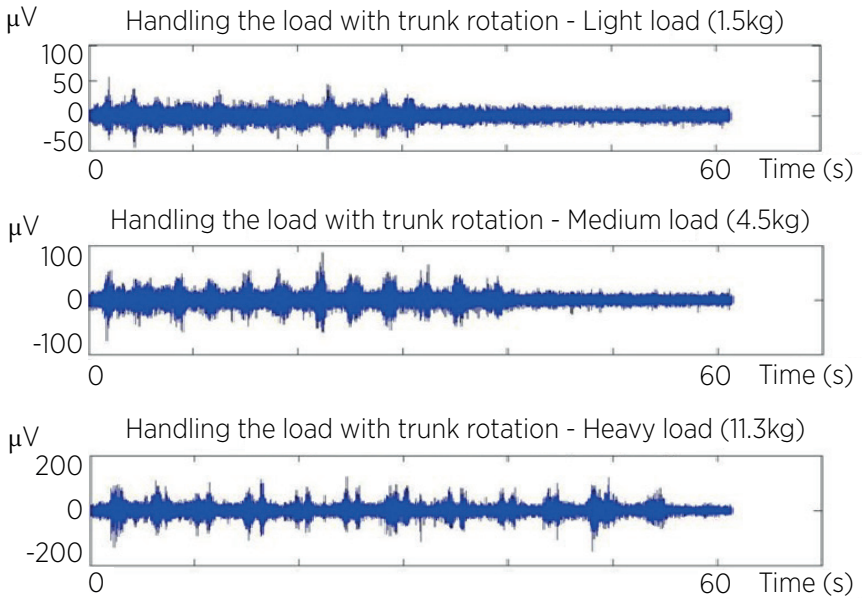

Figure 3. Raw data form one subject during manual materials handling: A) Sustaining the load; B) Handling the load without trunk rotation; C) lifting and lowering the load with trunk rotation. 


\section{Data analysis}

The three systems started simultaneously by a connection synchronization cable. The data were digitized simultaneously to the collection and stored. Then, data was processed using a routine developed in MatLab (Mathworks Inc., Natick, MA, USA).

For the analysis of the muscular activity and the kinematic pattern among the different activities, the data were descriptively analyzed. Normality (Shapiro Wilks) and homoscedasticity (Levene) tests were applied to test the assumptions for parametric tests. For the analysis of the difference between light, medium and heavy loads, within the tasks, a repeated measure ANOVA was performed. The analyses were conducted using SPSS (version 11.5) at a 5\% level of significance $(\alpha=0.05)$.

\section{RESULTS}

Table 1 shows the participants' demographic and clinical data. The participants had a mean age of 23 years, $\mathrm{BMI}$ within the eutrophic range, mean use of contraceptive of 4.6 years, and average of the sports activity index of 3.0 points. For the functional evaluation of PFMs, it was observed that the group obtained an average of 3.2 points for Power, which is equivalent to a moderate contraction in the modified Oxford scale; 6.5 seconds of sustained contraction for Endurance, four contractions until the fatigue for the Repeat and eight fast contractions for Fast. Regarding the manometry, the mean resting value was $42.6 \mathrm{mmHg}$ and the contraction force was $51.8 \mathrm{mmHg}$.
Table 2 shows the results of the electromyographic data of the lumbar, abdominal and pelvic floor muscles, as well as inclinometry data of lumbar spine flexion and inclination, for each task. The analysis of the differences between the loads showed that, within the different tasks, as the load increases the greater the activation of the lumbar and abdominal musculature. This pattern is also reflected in the kinematics of the lumbar spine, in which higher values of inclination and flexion were found in the manual material handling task with trunk rotation. For PFM activation, no difference was found between the loads in any task. The power of the tests for these analyses was low, ranging from 0.14 to 0.25 .

Table 1. Participants' demographic and clinical data $(n=16)$

$\begin{array}{lr}\text { Demographic characteristics } & \text { mean (SD) } \\ \text { Age (years) } & 23.2(4.0) \\ \text { Weight }(\mathrm{kg}) & 61.7(9.1) \\ \text { Height }(\mathrm{m}) & 1.60(0.1) \\ \text { Body mass index }\left(\mathrm{kg} / \mathrm{m}^{2}\right) & 23.0(2.5) \\ \text { Contraceptive (years) } & 4.6(4.7) \\ \text { Physical activity index (Baecke) } & 3.0(0.7) \\ \text { Vaginal palpation } & \\ \text { Power (0-5 points) } & 3.2(0.9) \\ \text { Endurance (seconds) } & 6.5(2.4) \\ \text { Repeat (number of repetitions) } & 4.3(1.2) \\ \text { Fast (number of repetitions) } & 7.9(1.6) \\ \text { Manometry (mmHg) } & \\ \text { Rest } & 42.6(7.9) \\ \text { Contraction } & 51.8(23.1)\end{array}$

Table 2. Electromyography data. Data are presented as mean and standard deviation

\begin{tabular}{|c|c|c|c|c|}
\hline & Light & Load & Heavy & $\mathbf{P}$ \\
\hline \multicolumn{5}{|l|}{ Left Iliocostal } \\
\hline Sustain the load* & $0.1(0.1)$ & $0.1(0.1)$ & $0.3(0.1)$ & 0.01 \\
\hline Handling without rotation & $0.5(0.3)$ & $0.6(0.3)$ & $0.8(0.4)$ & 0.10 \\
\hline Handling with rotation** & $0.5(0.3)$ & $0.7(0.3)$ & $0.8(0.4)$ & $<0.01$ \\
\hline \multicolumn{5}{|l|}{ Right Iliocostal } \\
\hline Sustain the load ${ }^{\beta}$ & $0.1(0.1)$ & $0.1(0.03)$ & $0.2(0.1)$ & 0.01 \\
\hline Handling without rotation ${ }^{\beta \beta}$ & $0.5(0.3)$ & $0.6(0.3)$ & $0.7(0.4)$ & 0.03 \\
\hline Handling with rotation ${ }^{\beta \beta \beta}$ & $0.4(0.3)$ & $0.6(0.4)$ & $0.7(0.5)$ & $<0.01$ \\
\hline \multicolumn{5}{|l|}{ Left Multifidus } \\
\hline Sustain the load ${ }^{\ddagger}$ & $0.1(0.1)$ & $0.2(0.1)$ & $0.3(0.2)$ & $<0.01$ \\
\hline Handling without rotation & $0.6(0.2)$ & $0.7(0.2)$ & $0.9(0.3)$ & 0.08 \\
\hline Handling with rotationff & $0.6(0.2)$ & $0.7(0.2)$ & $1.0(0.3)$ & $<0.01$ \\
\hline
\end{tabular}


Table 2. Continuation

\begin{tabular}{|c|c|c|c|c|}
\hline \multirow{3}{*}{ Right Multifidus } & \multirow[t]{2}{*}{ Light } & Load & \multirow[t]{2}{*}{ Heavy } & \multirow[t]{2}{*}{$\mathbf{P}$} \\
\hline & & Medium & & \\
\hline & & & & \\
\hline Sustain the load€ & $0.1(0.1)$ & $0.2(0.04)$ & $0.3(0.1)$ & $<0.01$ \\
\hline Handling without rotation $€ €$ & $0.6(0.3)$ & $0.7(0.3)$ & $0.9(0.4)$ & 0.02 \\
\hline Handling with rotation $\epsilon^{€ €}$ & $0.5(0.2)$ & $0.8(0.3)$ & $0.9(0.2)$ & $<0.01$ \\
\hline \multicolumn{5}{|l|}{ Left Abdominal } \\
\hline Sustain the load & $0.2(0.1)$ & $0.2(0.1)$ & $0.4(0.4)$ & 0.19 \\
\hline Handling without rotation & $0.4(0.3)$ & $0.7(0.6)$ & $0.6(0.4)$ & 0.06 \\
\hline Handling with rotation ${ }^{\alpha}$ & $0.3(0.3)$ & $0.4(0.3)$ & $0.9(0.6)$ & $<0.01$ \\
\hline \multicolumn{5}{|l|}{ Right Abdominal } \\
\hline Sustain the load & $0.2(0.1)$ & $0.2(0.1)$ & $0.4(0.4)$ & 0.14 \\
\hline Handling without rotation & $0.4(0.3)$ & $0.7(0.6)$ & $0.7(0.5)$ & 0.11 \\
\hline Handling with rotation ${ }^{\mu}$ & $0.3(0.3)$ & $0.5(0.3)$ & $0.9(0.7)$ & 0.03 \\
\hline \multicolumn{5}{|l|}{ Pelvic Floor } \\
\hline Sustain the load & $2.5(3.9)$ & $2.7(3.0)$ & $2.4(3.1)$ & 0.40 \\
\hline Handling without rotation & $5.9(9.0)$ & $8.0(9.4)$ & $8.3(7.8)$ & 0.22 \\
\hline Handling with rotation & $4.7(7.5)$ & $4.6(4.6)$ & $7.8(9.3)$ & 0.25 \\
\hline \multicolumn{5}{|l|}{ Flexion } \\
\hline Sustain the load & $2.2(8.5)$ & $1.7(8.5)$ & $-0.5(8.6)$ & 0.31 \\
\hline Handling without rotation & $22.0(12.5)$ & $23.0(15.9)$ & $27.2(14.9)$ & 0.61 \\
\hline Handling with rotation ${ }^{\theta}$ & $23.9(11.8)$ & $30.0(12.7)$ & $31.5(14.8)$ & $<0.01$ \\
\hline \multicolumn{5}{|l|}{ Inclination } \\
\hline Sustain the load & $-0.3(2.2)$ & $-1.0(2.7)$ & $-0.1(3.1)$ & 0.65 \\
\hline Handling without rotation & $2.4(2.2)$ & $3.3(2.8)$ & $4.3(2.2)$ & 0.08 \\
\hline Handling with rotation ${ }^{\theta \theta}$ & $2.5(2.2)$ & $4.2(2.4)$ & $5.8(3.1)$ & 0.03 \\
\hline
\end{tabular}

Post-hoc analysis found differences between loads: $*$ light and heavy $(p=0.02)$ and medium and heavy $(p=0.006) ;{ }^{*}$ light and heavy $(p=0.004)$ and light and medium ( $\left.p=0.006\right) ;{ }^{\beta}$ medium and heavy $(p=0.007)$

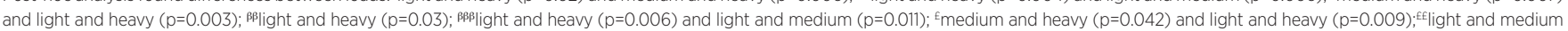

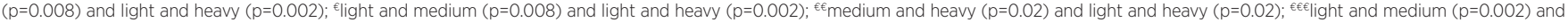

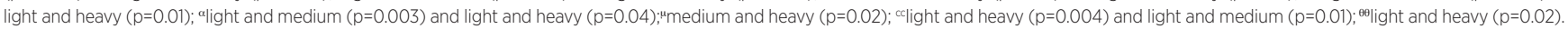

\section{DISCUSSION}

The main objective of our study was to compare the electrical activity of the lumbar, abdominal and pelvic floor muscles during manual material handling with different loads. The results indicated that the heavier the load, the greater is the activation of the lumbar and abdominal musculature. This pattern is also reflected in lumbar spine kinematics, in which higher values of inclination and flexion were found in the rotation handling activity. However, PFM activation showed no difference among the loads in any task.

Some studies have examined the effects of body shifts on the tonic activity of PFMs ${ }^{3,20}$. There is evidence that poor lumbopelvic alignment may increase the overload on the PFMs and affect its activation ${ }^{21}$. Sapsford et al. ${ }^{22}$ found differences in PFM activation in different postures, evaluating women with no urinary complaints in sitting postures (with or without support, relaxed or not), finding lower PFM activity associated with lumbar lordosis reduction. Moreover, during postural disorders and tasks that challenge spinal stability, insufficient activation of PFMs may result in ineffective urethral closure ${ }^{23}$.

Higher lumbar spine overload is generated when heavier handling load is imposed. Yang, Marras and Best $^{18}$, found greater muscle activation in the erector muscles of the spine and rectus abdominis during the handling of a $11.3 \mathrm{~kg}$ load compared to a $2.3 \mathrm{~kg}$ load. Regarding lumbar movement, in the heavier loads, greater values of flexion and inclination were found during the handling with rotation. This pattern can lead to increased overload for the extensor muscles and posterior ligaments of the spine ${ }^{24}$.

No difference was found for PFM activation among different loads. This finding was not expected and can be attributed to the low sample size. We could expect an increase in the electrical activation of the PFMs as the load increased, since the biomechanical activity of the PFMs in many movements acts synergistically with the abdominal musculature due to their communications by 
the muscular fasciae. This is the case of the transversus abdominis, which communicates with the pelvic floor by its fascia and, when requested, stabilizes the trunk in several movements and recruits the PFMs to assist in maintaining this posture ${ }^{22}$. The musculature of the transversus abdominis is more recruited as the demand or load of exercise increases ${ }^{25}$.

Regarding muscular synergism, some authors suggest that the active contraction of other muscles associated with the contraction of the PFMs increases its electrical activity ${ }^{26}$. Hodges et al. ${ }^{1}$ demonstrated that there is an increase in $\mathrm{PFM}$ response during deltoid muscle contraction as part of an anticipatory postural adjustment. Thus, we expected an increase of the activation as the load increased because of the role of the PFMs in the support of the spine and pelvis and postural control, besides the coactivation between the abdominal musculature and the PFMs.

As expected, our findings showed a synergism in the electrical activation of the lumbar and abdominal musculature simultaneously with changes in the lumbar spine kinematics, evidencing that one segment is connected to the other, which implies a joint and complete approach of both musculatures in the treatment of possible dysfunctions.

\section{Limitations and perspectives}

Our study was conducted with a convenience sample of young continent and asymptomatic women. The main limitation of our study is the small population size, which was composed by women between 18 and 35 years (median 26). Thus, the results cannot be generalized to other populations. The number of subjects should be higher to increase the power of the statistical tests. Future studies could evaluate other activities to assist in the development and improvement of effective therapeutic treatments for pelvic floor muscle dysfunctions. We recommend applying this protocol in incontinent women; if these findings are confirmed in incontinent woman, there could be implications for manual material handling training.

\section{CONCLUSION}

The activation of the lumbar and abdominal musculature increased at heavier loads; however, no difference was found for PFM activation on women without pelvic floor dysfunctions that could voluntarily contract the PFMs.

\section{REFERENCES}

1. Hodges PW, Sapsford R, Pengel LH. Postural and respiratory functions of the pelvic floor muscles. Neurourol Urodyn. 2007;26(3):362-71. doi: 10.1002/nau.20232

2. Franceschet J, Sacomori C, Cardoso FL. Strength of pelvic floor muscles and sexual function during pregnancy. Braz J Phys Ther. 2009;13(5):383-9. doi: 10.1590/S1413-35552009005000054

3. $B \varnothing \mathrm{K}$, Finckenhagen $\mathrm{HB}$. Is there any difference in measurement of pelvic floor muscle strength in supine and standing position? Acta Obstet Gynecol Scand. 2003;82(12):1120-4. doi: 10.1046/j.1600-0412.2003.00240.x

4. Madill S, Harvey MA, McLean L. Women with SUI demonstrate motor control differences during voluntary pelvic floor muscle contractions. Int Urogynaecol J Pelvic Floor Dysfunct. 2009;20(4):447-59. doi: 10.1007/s00192-008-0800-y

5. Sjödahl J, Kvist J, Gutke A, Oberg B. The postural response of the pelvic floor muscles during limb movements: a methodological electromyography study in parous women without lumbopelvic pain. Clin Biomech. 2009;24(2):183-9. doi: 10.1016/j.clinbiomech.2008.11.004

6. Capson AC, Nashed J, McLean L. The role of lumbopelvic posture in pelvic floor muscle activation in continent women. J Electromyogr Kinesiol. 2011;21(1):166-77. doi: 10.1016/ j.jelekin.2010.07.017

7. Luginbuehl H, Baeyens JP, Taeymans J, Maeder IM, Kuhn A, Radlinger $L$. Pelvic floor muscle activation and strength components influencing female urinary continence and stress incontinence: a systematic review. Neurourol Urodyn. 2015;34(6):498-506. doi: 10.1002/nau.22612

8. Tamanini JTN, D’Ancona CAL, Botega NJ, Rodrigues Netto N Jr. Validação do questionário de qualidade de vida (King's Health Questionnaire) em mulheres brasileiras com incontinência urinária. Rev Saude Publica. 2003;37(2):203-11. doi: 10.1590/S0034-89102003000200007

9. Pinheiro FA, Tróccoli BT, Carvalho CV. Validação do Questionário Nórdico de Sintomas Osteomusculares como medida de morbidade. Rev Saude Publica. 2002;36(3):307-12. doi: 10.1590/S0034-89102002000300008

10. Florindo AA, Latorre MRDO. Validação e reprodutibilidade do questionário de Baecke de avaliação da atividade física habitual em homens adultos. Rev Bras Med Esporte. 2003;9(3):121-8.

11. Laycock J, Jerwood D. Pelvic floor muscle assessment: the perfect scheme. Physiotherapy. 2001;87(12):631-42. doi: 10.1016/S0031-9406(05)61108-X

12. Hansson GA, Asterland P, Holmer NG, Skerfving S. Validity and reliability of triaxial accelerometers for inclinometry in posture analysis. Med Biol Eng Comput. 2001;39(4):405-13. doi: 10.1007/bf02345361

13. Surface Electromyography for the Non-Invasive Assessment of Muscles. Welcome at Seniam.org [Internet]. Enschede: SENIAM; 2012 [cited 2014 Sept 12]. Available from: http://www.seniam.org

14. Vera-Garcia FJ, Moreside JM, McGill SM. MVC techniques to normalize trunk muscle EMG in healthy women. J Electromyogr Kinesiol. 2010;20(1):10-6. doi: 10.1016/j.jelekin.2009.03.010 
15. Veiersted KB, Forsman M, Hansson GA, Mathiassen SE. Assessment of time patterns of activity and rest in full-shift recordings of trapezius muscle activity - Effects of the data processing procedure. J Electromyogr Kinesiol. 2013;23(3):540-7. doi: 10.1016/j.jelekin.2012.12.004

16. Pereira VS. Métodos de avaliação da musculatura do assoalho pélvico feminino [dissertation]. São Carlos: Universidade Federal de São Carlos; 2013 [cited 2020 Nov 4]. Available from: https://repositorio.ufscar.br/handle/ufscar/5165

17. Wagner DW, Reed MP, Chaffin DB. The development of a model to predict the effects of worker and task factors on foot placements in manual material handling task. Ergonomics. 2010;53(11):1368-84. doi: 10.1080/00140139.2010.523482

18. Yang G, Marras WS, Best TM. The biochemical response to biomechanical tissue loading on the low back during physical work exposure. Clin Biomech. 2011;26(5):431-7. doi: 10.1016/ j.clinbiomech.2011.01.005

19. Silva LCCB, Oliveira AB, Silva DC, Paschoarelli LC, Coury HJCG. Evaluation of reusable cardboard box designs: biomechanical and perceptual aspects. Int J Ind Ergon. 2003;43(2):154-60. doi: 10.1016/j.ergon.2012.12.001

20. Kelly M, Tan BK, Thompson J, Carroll S, Follington M, Arndt A, et al. Healthy adults can more easily elevate the pelvic floor in standing than in crook-lying: an experimental study. Aust J Physiother. 2007;53(3):187-91. doi: 10.1016/S0004-9514(07)70026-0
21. Fozzatti MCM, Palma P, Herrmann V, Dambros M. Impacto da reeducação postural global no tratamento da incontinência urinária de esforço feminina. Rev Assoc Med Bras. 2008;54(1):1722. doi: 10.1590/S0104-42302008000100015

22. Sapsford RR, Richardson CA, Maher CF, Hodges PW. Pelvic floor muscle activity in different sitting postures in continent and incontinent women. Arch Phys Med Rehabil. 2008;89(9):1741-7. doi: 10.1016/j.apmr.2008.01.029

23. Smith MD, Coppieters MW, Hodges PW. Postural activity of the pelvic floor muscles is delayed during rapid arm movements in women with stress urinary incontinence. Int Urogynecol J Pelvic Floor Dysfunct. 2007;18(8):901-11. doi: 10.1007/s00192-006-0259-7

24. Maduri A, Pearson BL, Wilson SE. Lumbar-pelvic range and coordination during lifting tasks. J Electromyogr Kinesiol. 2008;18(5):807-14. doi: 10.1016/j.jelekin.2007.02.012

25. Korelo RIG, Kosiba CR, Grecco L, Matos RA. Influência do fortalecimento abdominal na função perineal, associado ou não à orientação de contração do assoalho pélvico, em nulíparas. Fisioter Mov. 2011;24(1):75-85. doi: 10.1590/S0103-51502011000100009

26. Resende A, Nakamura M, Ferreira E, Petricelli C, Alexandre S, Zanetti M. [Evaluation of female pelvic floor muscles using surface electromyography: literature review]. Fisioter Pesqui. 2011;18(3):292-7. doi: 10.1590/S1809-29502011000300016 